\title{
CONTINGENT EFFECTS OF HUMOR TYPE AND COGNITIVE STYLE ON CONSUMER ATTITUDES
}

\author{
James Mark Mayer, Indiana University, USA, jammayer@iupui.edu \\ Plamen Peev, Towson University, USA, ppeev@towson.edu \\ Piyush Kumar, University of Georgia, USA, pkumar@uga.edu
}

\begin{abstract}
In the spirit of examining humor contextually, we consider a basic question in this essay: do different humor types "play by the same rules," cognitively speaking? We examine the relationship between humor and cognitive processing style, as operationalized through Need for Cognition. We find that humor based on disparagement processes "breaks through" the cognitive differences inherent in incongruity humor. Rather than exhibiting incongruity-based humor's affective response transferring to attitude for low-NFC subjects, and more centrally-employing high NFC subjects' higher tendency to dismiss the humor's effect on overall attitude, disparagement based humor is processed the same by both low- and high-NFC respondents. Overall, our findings suggest that the relationship between cognitive processing (as operationalized through Need for Cognition) and resultant attitudes is a complicated one, strongly contingent on humor type. Were only incongruity-based humor utilized, our findings would have reinforced Zhang's (1996b) assertion that a person's Need for Cognition will play a key role in the evaluation of humor, but our results suggest that a more complex conceptualization of the relationship between humor and attitude formation is required when humor is treated as a potentially more complicated, context-dependent construct.
\end{abstract}

Keywords: Humor, Cognitive Processing, Attitude Formation, Humor Type

\section{INTRODUCTION}

This paper explores the link between a consumer's underlying motivation to engage in cognitive activity (Need for Cognition, or NFC) and the efficacy of different types of humor. Humor stands as one of the most utilized execution elements in consumer communication as various forms of it are employed in around 20\% of television advertisements (Beard 2008). There is no debating that advertisers have certainly leveraged humor in advertising, but there is substantial debate as to the efficacy of humorbased marketing communication efforts. Humor research has been complex; after undertaking a comprehensive review of the use of humor in advertising, Weinberger and Gulas (1992) conclude that "broad generalizations about the effect of humor in advertising are inappropriate" (p. 56). In this contextual spirit, the authors attempt to explicate the relationship of different types of humor (incongruity-based and disparagement-based) and consumer processing tendency

\section{COGNITION AND PROCESSING STYLE}

Researchers in a variety of fields have attempted to explicate attitude formation and change processes. Traditional theories stress the dominant role of effortful cognition in attitude formation. However, over the past few decades, researchers have been interested not only in cognitive-based effortful processing, but more "effortless" or automatic processing as well. One such theory, the Elaboration Likelihood Model (ELM), is offered by Petty and Cacioppo (1981). The model features an elaboration likelihood continuum, where consumer persuasion after exposure to a stimulus depends on the degree to which

This is the author's manuscript of the article published in final edited form as:

Mayer, J. M., Peev, P., \& Kumar, P. (2016). Contingent Effects of Humor Type and Cognitive Style on Consumer Attitudes. In Let's Get Engaged! Crossing the Threshold of Marketing's Engagement Era (pp. 739-751). Springer International Publishing. http://dx.doi.org/10.1007/978-3-319-11815-4_223 
people elaborate on the information embedded within that stimulus. This theory posits that in a central processing, high-elaboration-likelihood situation, cognition ("think about something, and then form attitudes") will largely drive attitude formation. However, rather than taking the central role of cognition as a given, the model posits that when an individual engages in peripheral processing, various environmental cues may be used as "shortcuts" in attitude formation. Whether a person adopts a more central or more peripheral processing style is a function of individual differences and situational factors.

Cacioppo and Petty (1982) define Need for Cognition (NFC) as "the tendency for an individual to engage in and enjoy thinking" (p. 116). The construct resulted from factor-analytic examinations of individuals' variation in this tendency; as Cacioppo, Petty, Feinstein, and Jarvis (1996) write, "much of the interindividual variation in people's tendency to engage in and enjoy effortful cognitive endeavors could be represented in terms of a single factor, which was called need for cognition" (p. 197).

NFC is one of recent history's most influential individual difference variables, having been extensively researched over the past 25 years and demonstrated to be related to other individual difference variables such as locus of control (Fletcher et al. 1986) as well as to moderate expectancies of success and achievement (Dickhauser and Reinhard 2006) and attitude change (Petty et al. 1993). NFC has been shown to influence the ultimate processing route that an individual uses (Cacioppo and Petty 1982), as low-NFC individuals tend to rely more on peripheral cues, whereas high-NFC individuals usually engage in high-elaboration central processing. The construct measures an individual's intrinsic motivation and not intellectual ability (Cacioppo et al. 1996), and persons high (compared to low) on NFC usually demonstrate a more positive attitude toward stimuli and tasks which are characterized by or require greater cognitive effort. Since high-NFC individuals generally process information more deeply than those low in NFC (Cacioppo and Petty 1982), they are more likely to discount stimulus elements that they deem irrelevant as input to overall attitude formation.

\section{COGNITION AND HUMOR}

One of the dominant theories in humor research over the past two centuries has been IncongruityResolution. It can be described generally as exposure to a stimulus that is "incongruous, surprising, peculiar, unusual, or different from what we normally expect" (Martin 2007, p. 63) which is resolved in a way that causes it to make sense. Incongruity theory is central to many modern theories of humor; for example, Raskin's (1985) Semantic Script Theory, described by Simpson (2003) as: "A text is a joke if: The text fits with (either wholly or partially) two different scripts (i.e., a knowledge structure)" and "the two scripts are opposite in a special sense" (p. 30). Theorists embracing this perspective typically view some types of incongruity as being a defining characteristic of humor (e.g., Apter 1982); for instance, Ruch (1988, p. 861) writes that "two structural parameters are considered to be essential ingredients in all kinds of humour: incongruity... and the resolution of the incongruity" and Ruch and Hehl write "there is general agreement about the existence of this two-stage structure in the process of perceiving and understanding humor" (1998, p. 114). Thus, incongruity-resolution has been presented by some as an essential characteristic of humor.

While the degree to which an individual is motivated to elaborate on a stimulus has limited face validity as a predictor of how funny that individual will perceive a stimulus to be, it may play an important differential role in the resulting attitude formation. In general, humor has been hypothesized to be more subject to peripheral than central processing (Martin 2007), but whether a humorous message influences 
resultant attitude formation might vary depending on the cognitive motivation of the message recipient or the strength of the advertising claims (Cline and Kellaris 1999). For instance, in an advertising setting, highly motivated, central processors who score high on NFC might base their attitudes on relevant, useful information (e.g., objective product ratings) and ignore peripheral aspects like humor, whereas low-NFC individuals may use a "this is funny, so I like it"-type heuristic and thus allow humor evaluation a direct effect on attitude formation. While past research has indicated that humor presence generally increases favorable attitudes toward an object (e.g., an advertisement), this basic process is likely to work differently for low- and high-NFC individuals, with those low on NFC being more likely to rely on peripheral cues in forming attitudes toward an object, thus making the conventional wisdom of "humor increases liking" more likely to occur. In other words, a low-NFC message recipient may let a basic affective response ("this is funny") shape his or her overall attitude of the humorous object ("this is funny, so I like this"). Along the same lines, a high-NFC person is less likely to allow an affective cue ("this is funny") to shape his or her overall attitude and will likely seek to engage cognitively when developing that attitude. Similarly to how attractiveness bias is less pronounced in high-NFC versus low-NFC participants, a "humor bias" of sorts will play less of a role in high-NFC versus low-NFC subjects in forming overall attitudes towards an object.

Zhang (1996a; 1996b) found evidence of this phenomenon, with brand attitudes and purchase intent measured after participants' exposure to print humorous ads lower (higher) for participants with high (low) NFC scores. Interestingly, Geuens and De Pelsmacker (2002) failed to replicate those results finding that humor had a universally positive effect on respondents' attitudes towards advertisements and the advertising brands. Both Zhang and Geuens and De Pelsmacker used incongruity-resolution based humor in an advertising setting, but it is worth noting that while Zhang's humorous manipulation (a cartoon with a pun about "shooting first and asking questions later") was tied directly to the brand (a camera, with the ad pointing out the need to "ask questions" before "shooting pictures"), Geuens and De Pelsmacker's stimulus was unrelated to the brand.

\section{HUMOR PROCESSES: BEYOND COGNITION}

Different underlying processes have been theorized as causing humor beside incongruity-resolution. For instance, humor is often hypothesized as stemming from a disparagement process. In disparagement, the humor functions as an attempt at establishing superiority, a tool to "include" some and "isolate" others (e.g., ethnic and sexist humor), or to allow us to "feel we are better than others" (Beard 2008, p. 47). This conceptualization treats humor as a form of aggression; as Martin (1998) writes, "Aristotle, for example, concluded that laughter arises primarily in response to weakness and ugliness" (p. 29). Hobbes shared this view, and in the $18^{\text {th }}$ century ridicule was a popular technique of debate. Many prominent researchers continue to espouse the importance of disparagement in the genesis of humor, a sentiment echoed by Gruner (1996) who asserts that "to understand a piece of humorous material it is necessary only to find out who is ridiculed, how, and why" (as cited in Martin 1998, p. 29). Disparagement, when coupled with a playful cue indicating that a stimulus is humorous and not simply mean or abusive, is at the heart of a significant amount of humorous communication.

Speculation that different humor types may be processed differently has been researched with some success. For instance, Goel and Dolan (as cited in Martin 2007) examined brain activity by utilizing magnetic resonance imaging (MRI), finding that participants listening to jokes featuring more complex incongruity (i.e., semantic jokes) more extensively utilized temporal lobes involved in language 
understanding, while those who listened to sound-based simple puns (i.e., phonological jokes) more extensively utilized the speech-processing left frontal lobe. Per the consideration here, given their inherently different natures (i.e. conative versus cognitive), it is posited that disparagement- and incongruity-based humor may result in differing application, based on cognitive processing differences, of humor evaluation. Whereas incongruity-based humor is a less personally involving process, the more personal, conatively driven disparagement humor might be more difficult for low-NFC participants to simply treat as a peripheral cue.

The Encyclopedia of Psychology entry under "Motivation: Philosophical Theories" describes the difference between cognitive and conative aspects as cognitive states having "a more subordinate role [in motivation]," whereas a more conative process is "capable of triggering action." It is speculated here that humor based on disparagement could theoretically "break through" the cognitive "barrier" characteristic of incongruity-driven humor. In other words, if a humorous advertisement featured strong disparagement humor, it may be more transparent to consumers and, in turn, the humor may have a greater effect on resultant evaluations. Rather than exhibiting the differential effects of incongruitybased humor on attitudes across low- and high-NFC individuals, whereby affective response directly transfers to attitude for low-NFC, but not high-NFC message recipients who display a tendency to employ central processing that weakens the humor's effect on overall attitude, disparagement based humor might be processed centrally by both low- and high-NFC respondents. Thus, this research posits that moving from incongruity-based humor to disparagement-based humor should effectively erase any NFC-driven attitudinal differences.

\section{HYPOTHESES}

Based on the preceding conceptual development, authors offer the following formal hypotheses:

H1a: In an incongruity-based humor setting, participants will assign a higher humor evaluation to a humor-containing stimulus than a non-humorous stimulus.

H1b: In a disparagement-based humor setting, participants will assign a higher humor evaluation to a humor-containing stimulus than a non-humorous stimulus.

H2a: The effect of incongruity-based humor on corresponding attitudes will be moderated by a participant's NFC, whereby attitudes of participants lower in NFC will be higher in the presence of humor compared to when humor is not present, but for participants higher in NFC, humor will have no effect on attitudes.

$\mathrm{H} 2 \mathrm{~b}$ : The effect of disparagement-based humor on corresponding attitudes will not be moderated by participants' NFC.

\section{STIMULUS DEVELOPMENT AND PRETESTS}

A five-step pretesting process was conducted to find a source image to use in conducting the experiment. In the first step of the process, an internet search was performed to select a number of pictures that would form the core of the stimuli. As the authors needed to utilize a non-humorous control condition, pictures that were prima-facie humorous in and of themselves, such as a baby in large sunglasses, were discarded. Pictures that would not easily lend themselves to humor, such as 
photographs of a cemetery, were also discarded. A total of 15 pictures were selected from the initial set after discarding ones that did not meet the aforementioned criteria. Next, attitudes towards these pictures were tested. Thirty-nine undergraduate students, who volunteered to participate in the study, were each presented with a fifteen-page booklet, with each page containing one of the pictures and scales measuring humor evaluation and attitude towards the picture (henceforth $\mathrm{A}_{\text {picture }}$ ). Three students declined to reveal their gender, and thus thirty-six usable booklets (20 female, 16 male) were obtained. Humor evaluation was measured using a six-item, seven-point, semantic differential scale (Chattopadhyay and Basu 1990) (humorous/not humorous, funny/not funny, amusing/not amusing,

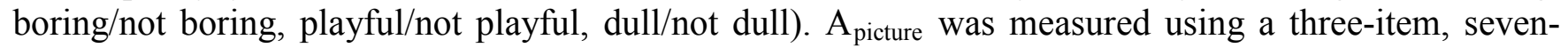
point semantic scale (favorable/unfavorable, good/bad, like very much/dislike very much). Reliabilities were above the commonly accepted cut-off for Cronbach's $\alpha$ of .80 for all but one picture, with humor evaluation reliabilities ranging from $\alpha=.85$ to $\alpha=.94$ and $A_{\text {picture }}$ reliabilities ranging from $\alpha=.81$ to $\alpha=.95$.

To test for gender differences, a series of one-way ANOVAs with gender as the independent variable and humor evaluation and $\mathrm{A}_{\text {picture }}$ as dependent variables were run. No significant differences were found with humor evaluation as the dependent variable (all $F^{\prime}$ 's $<1.58$, all $p$ 's $>.10$ ). However, some gender differences in the attitude towards the picture were observed. The attitude scores of the male participants were higher for pictures of a laptop $(\mathrm{M}=5.1$ vs. $4.3, F(1,34)=6.5, \mathrm{p}<.02)$, a yacht $(\mathrm{M}=$ 5.0 vs. $4.3, F(1,34)=4.8, \mathrm{p}<.04)$, and people skiing $(\mathrm{M}=4.8$ vs. $4.3, F(1,34)=4.2, \mathrm{p}<.05)$. Male participants' attitudes were also directionally lower for a picture of a picnic $(\mathrm{M}=4.0 \mathrm{vs} .3 .5, F(1,34)=$ $2.9, \mathrm{p}<.10)$. Female relative to male participants had a marginally higher score for a picture of shoppers $(\mathrm{M}=4.4$ vs. $4.0, F(1,34)=2.4, \mathrm{p}<.14)$. Next, subjects' attitudes towards the pictures were evaluated. The mean attitude scores varied considerably, with "skydivers" $(\mathrm{M}=4.3)$ scoring the highest, and "traffic jam" $(\mathrm{M}=1.7)$ the lowest. The attitudinal differences between these highest and lowest liked pictures were statistically significant $(t(35)=9.2, p<.01)$. In order to avoid both potential ceiling effects and a situation where participants would fundamentally dislike the source object, the authors sought pictures that were "moderately liked", that is, those whose attitude rating was significantly higher than the rating of the lowest rated picture ("traffic jam"), but significantly lower than the rating of the best-liked one ("skydivers"). Thus, pictures of an airport $(\mathrm{M}=2.1)$ and a broken-down car $(\mathrm{M}=1.9)$ were eliminated because their ratings were similar to that of the picture of the traffic jam (both $p$ 's $>$.10). In terms of humor evaluation, the picture with the highest mean score ("skydivers", $M=4.2$ ) was rated significantly funnier than any other picture $(p<.01)$ and was discarded. This left us with four options that met all three objectives of the pretest for the humor setting -"bike riders", "dancers", "joggers", and "yard sale" - which were used for the remaining steps of the stimulus development process.

Next, three captions to accompany every picture were developed. The first one was merely descriptive of the picture and contained no humor. The second one contained disparagement-based humor, while the third one contained incongruity-based humor. We next conducted two pretests to ensure that the humor processes had been correctly operationalized through the selected captions. First, we asked two judges whether or not they thought the captioned pictures successfully achieved the humor presence as well as the intended dominant humor processes (incongruity-resolution or disparagement) when humor was present. A training manual was prepared and used in familiarizing the judges with the two humor processes. In addition to seeing the examples of each humor process provided in the manual, judges were asked to think of examples that they could recall having seen. Each training session lasted approximately one hour. One week later, the judges were given a brief refresher on the processes and 
started coding the captioned pictures independent of each other by completing a forty-five page booklet. Each page contained a captioned picture (one of the 15 pictures and either a no-humor, disparagementbased humor, or incongruity-based humor caption). Care was taken to make the judging a challenging endeavor in order to minimize the possible capitalizing on chance; therefore, judges were instructed that the three captions accompanying each picture are not necessarily of the three different types, even though they always were. Finally, judges were given a fourth answer option, "other humor type", for the instances when they thought humor was present, but they felt neither disparagement nor incongruityresolution were responsible for it. To sum up, for each captioned picture, judges first determined whether or not humor was present, and if they answered yes, they were instructed to determine what the dominant humor process (disparagement, incongruity, or "other") was. For each of the 45 captioned pictures the judges correctly identified the non-humorous and the humorous ones. The judges agreed on the second question (dominant humor process) 26 out of 30 times $(87 \%)$. The three pictures that had at least one caption with disagreement between the judges ("airport", "bike riders", and "broken-down car") were deemed to have failed the pretest.

Second, authors confirmed this expert evaluation through a pretest with participants similar to those we would use in the studies. Thirty-three undergraduate students were given a lecture on humor processes and reviewed examples of disparagement- and incongruity-based humor. During the next 30 minutes the students were split into 8 groups. Each group had between three and five members and there was at least one male and one female on every team. Each group was given one fifteen-page booklet to complete. Each page contained one of the pictures, and the three captions that went with it. The groups were asked to identify whether humor was present in each caption, and if so, what the dominant humor process was ("other humor process" was again included as an option). The groups worked independently of each other. While, once again, all no-humor captions were correctly identified, group responses for only two of the source pictures ("hiking" and "yard sale") had 100\% agreement with the hypothesized humor processes. The rest of the potential stimuli were discarded.

Thus, ultimately, one picture-caption set ("yard sale") emerged as the optimal stimulus for the situation. The picture was simply an image of a yard sale in progress, with a few people in the midst of it. The non-humorous caption was "Lots of great bargains can be found at a yard sale," the incongruity-humor caption was "Sure, the basketball hoop is for sale_-but you have to get it down!" and the disparagementhumor caption was "I can't believe I paid money for this junk when it was new, much less that these jokers are buying it used!"

\section{EXPERIMENT}

\section{Method and Participants}

Participants were 157 students at a large American university. Students were instructed that their participation in the study was completely voluntary. They completed the study during undergraduate class sessions, following a guest lecture by one of the authors. The study was in the form of a penciland-paper booklet which contained a captioned picture (the moderately-liked "yard sale" picture) with either a humorous or a non-humorous caption, dependent measures, and an NFC scale, all interspersed among other non-related exercises. Attitude and humor evaluation were measured through the same scales used in the first pretest: humor evaluation was measured using a six-item, seven-point, semanticdifferential scale (Chattopadhyay and Basu 1990; humorous/not humorous, funny/not funny, 
amusing/not amusing, boring/not boring, playful/not playful, dull/not dull) and attitude towards the captioned picture $\left(\mathrm{A}_{\mathrm{CP}}\right)$ was measured through a three-item, seven-point semantic-differential scale (favorable/ unfavorable, good/bad, like very much/dislike very much). Participants also completed the 18-item shortened NFC scale developed by Cacioppo, Petty, and Kao (1984). This scale has been found to be both valid and gender neutral in a number of studies (see Cacioppo et al. 1996). Each NFC item was measured on a five-point scale, with 5 representing "extremely characteristic," and 1 representing "extremely uncharacteristic." Half of the items were reverse scored. Participants completed the booklet, including non-related exercises, in approximately 20 minutes. Participants were then debriefed and thanked for their participation.

\section{Preliminary Validation}

A manipulation check was conducted to determine if both humor manipulations were successful. Gender was also included as an independent variable to ensure that the efforts to create gender-neutral humorous captioned pictures were successful. A two-way ANOVA was conducted with humor evaluation as dependent variable and humor type (no-humor, disparagement-based, incongruity-based) and gender (female, male) as the independent variables. Humor evaluation was significantly higher in the presence of both disparagement $(\mathrm{M}=4.53)$ and incongruity $(\mathrm{M}=4.64)$ humor types than when humor was not present $(M=2.21, F(5,150)=27.66, p<.01)$; post-hoc simple effect tests with Bonferroni adjustment of each humor type versus the control condition confirmed these differences were significant (both $p<$ .01). Thus, each humor manipulation was deemed successful. Further, there was neither a significant main effect of gender $(p>.47)$, nor a two-way interaction of humor presence $\mathrm{x}$ gender $(p>.19)$.

Reliability analyses indicated that the rating scales of both dependent variables were acceptable, with Cronbach's $\alpha=.94$ for the six-item humor evaluation composite, and $\alpha=.90$ for the four-item $\mathrm{A}_{\mathrm{CP}}$ composite. Likewise, the NFC scale was successfully implemented as Cronbach's $\alpha=.94$ with no individual item's deletion resulting in a substantially higher coefficient alpha.

\section{Results}

A series of regressions were conducted to test the hypotheses. Thus the three-level humor manipulation was coded into two variables according to the humor process present (DISP and INCON), with NFC treated as a continuous variable. Separate variables were created for the two-way interactions of humor presence and NFC (DISPxNFC and INCONxNFC). Per Aiken and West (1991), scores for the NFC scale were centered (the mean NFC score, 3.4156, was subtracted from each participant's NFC score) in order to reduce potential multicollinearity. The regression model with humor evaluation as dependent variable was significant $\left(F(5,151)=27.11, p<.01, R^{2}=.47\right)$ with significant main effects for both types of humor: disparagement-based $(\beta=.715, t(151)=5.20, p<.01)$ and incongruity-based $(\beta=.840, t(151)$ $=6.11, p<.01)$. No main effect was present for NFC $(p>.83)$. Likewise, the two-way interactions of NFC with each humor type were not significant (both $p>.31$ ) - individual differences in NFC didn't have an impact on humor evaluation. The results of the analogous regression with $\mathrm{A}_{\mathrm{CP}}$ as dependent variable were significant $\left(F(5,151)=7.94, p<.01, R^{2}=.21\right)$. This regression analysis revealed that, as predicted, there was no two-way interaction between the disparagement-based humor and NFC $(\beta=.21$, $t(151)=1.22, p>.22)$. There was, however, a two-way interaction of incongruity-based humor and NFC $(\beta=-.35, t(151)=-2.04, p<.05)$. These results provide initial support for the hypotheses that cognitive processing differences would indeed drive differential attitudinal results in the context of 
incongruity-based, but not disparagement humor. As expected, the latter universally increased attitude as evidenced by a main effect of disparagement-based humor $(\beta=.60, t(151)=4.39, p<.01)$ and the lack of the aforementioned DISPxNFC interaction.

Next, the two humor conditions were analyzed independently. Per the hypothesized effects, in the incongruity-humor condition, the $\beta$-coefficient of NFC was significant and negative $(\beta=-.707, t(49)=-$ $3.82, p<.01)$, whereas in the disparagement-humor condition it was not significant $(\beta=-.148, t(53)=-$ $.68, p>.50$ ). To explore the interaction of INCxNFC in more detail, a regression analysis on participants in the incongruity-based humor and no-humor conditions was conducted, which examined the interaction between NFC and incongruity presence ("yes" vs. "no") at values one standard deviation above and below the mean of NFC (Aiken and West 1991; Hayes 2013). For participants with low NFC (at least one standard deviation below the mean of NFC), there was a significant interaction of incongruity presence and NFC, $(\beta=-.733, t(103)=-4.07, p<.01)$. However, for participants with high NFC (at least one standard deviation above the mean of NFC), there was no significant interaction ( $\beta$ $=.26, t(103)=.15, p>.88)$. In sum, this study supports the above-formulated hypotheses. As expected, regardless of their differing cognitive motivation levels (NFC), participants by and large found the humorous captions (both incongruity-based and disparagement-based) to be funny. Simply stated, a person's NFC doesn't appear to influence his or her appreciation of humor. However, NFC-driven differences did emerge when considering the potential humor-to-attitude chain of effects: disparaging humor did not interact with NFC, while incongruity-based humor did indeed interact with NFC - a result supporting H2a and H2b, and Zhang's findings (1996a). It appears that participants with high NFC levels are more likely to discount humor evaluation in forming their attitudes, whereas participants with low NFC levels use humor as a peripheral cue ("this is funny, so I like it") in attitude formation.

\section{DISCUSSION}

Humor is widely utilized in consumer settings, and it is important for marketing practitioners to understand the individual differences that may effectively heighten or dampen its impact. When such a variable interacts with a prevalent advertising executional element, for instance, marketers would obviously be concerned with understanding that process. This investigation, however, demonstrates how contextually challenging leveraging humorous communication can be: there is not a simple across-theboard interaction between NFC and humorous content on resulting attitudes; instead, the relationship is rather nuanced and subtle.

In an incongruity-based humorous setting, when low-NFC participants viewed a humorous captioned picture, they allowed their affective reaction to the humor to color their overall attitude towards the captioned picture, an effect that did not occur with high-NFC participants. Given their preference for cognitive activity using central processing, the latter do not allow the humor evaluation to determine their attitude towards the stimuli. The effect - or lack thereof - of humor evaluation on attitude is in line with NFC's overall role as a motivational, not biological, personality variable. When humor is essentially a one-stage cognitive process (e.g., "is this funny?"), differences do not exist.

However, differences in respondents' processing style manifest themselves in defining the role of humor in attitude formation. Even then, the relationship between NFC and humor - and the resultant differential effect on attitudes - appears to be isolated to incongruity-based humor. This is not surprising, as this humor type offers perhaps the "best chance" for these cognitive processing differences 
to manifest themselves as incongruity-resolution humor has been identified as a mainly cognitive process and, therefore, the influence of a person's NFC in situations where such humor is present should be relatively strong. In contrast, disparagement-based humor is seen as employing a less cognitive and more conative process which should diminish NFC's role. In light of this distinction, it is not surprising that the relationship between NFC and humor is indeed contingent on the type of humor employed, with the more aggressive humor type in disparagement effectively erasing the differences between low- and high-NFC individuals. It could be speculated that this occurs because unlike incongruity-based humor which is processed differently by low- vs. high-NFC people, disparagement-based humor is likely processed centrally by both low- and high-NFC respondents.

Overall, the outcome of this study suggests that the relationship between cognitive processing (as operationalized through NFC) and resultant attitudes is a complicated one, strongly contingent on humor type. Were only incongruity-based humor utilized, the results would have reinforced Zhang's (1996b) assertion that an individual's preferred cognitive processing style will play a key role in how humor affects attitude formation, but the current findings suggest that a more complex conceptualization of humor may be required if the effect is to be fully understood.

\section{LIMITATIONS AND AREAS FOR FURTHER RESEARCH}

One key limitation of this research and potential area for further research stems from the fact that only two humor processes - incongruity-resolution and disparagement - were utilized. There are other major humor processes that would be appropriate for a similar investigation. For instance, the arousal-safety type humor that has been conceptualized as primarily affective in nature (Speck 1991) was not utilized. Another potential humor type that would perhaps be ideal for a similar examination is sexual humor. Given its very nature, sexual humor seems, at face value, likely to be processed centrally by consumers and may affect attitudes in a manner similar to disparagement-based humor. However, given the debate as to whether there are fundamental gender-based differences in sexual humor appreciation and the speculation that men and women may exhibit fundamental differences in how they process it, it would be interesting to investigate whether, in the presence of sexual humor, NFC interacts with biological gender to affect the formation of resulting attitudes. Such an investigation would provide a richer view of the contingent relationship between NFC and humor.

It also must be noted that the current studies were conducted in a non-marketing setting, as a simple captioned-picture stimulus was utilized. Although this was a conscious decision made in an attempt to avoid some of the potential confounds that Zhang (1996a; 1996b) and Geuens and De Pelsmacker (2002) faced, a key next step would be to examine the interplay of NFC and multiple humor types in a consumer setting (e.g., advertising). In particular, comparative advertising often seems to leverage disparaging humor (i.e., one brand mocking another) and although there is a rich literature on comparative advertising, there has been no investigation as to the efficacy of and the potential moderating and mediating variables in a humorous comparative advertising.

A further limitation is that other potentially pertinent personality variables were not included in the study. For instance, humor's effects are amplified in individuals high in Need for Humor (NFH), the motivation to process humorous stimuli (Kellaris and Cline 2007). These individuals consider humor to be an essential part of their lives, and self-identify as experts in its use. The relationship between NFH and NFC has also been explored, and their interaction has been shown to influence the effect of humor 
on responses to ads (Cline, Altsech, and Kellaris 2003). Given that these studies, and much of our knowledge of humor's effects on advertising efficacy, have been researched using incongruityresolution type humor, an important next step would be to explore disparagement-based and potentially other types (e.g., sexual) through the lens of Need for Humor.

Finally, the sample of American undergraduate students this research was fielded with represents a serious limitation of the study. As humor has been demonstrated to possess universal as well as culturespecific elements (Alden, Hoyer, and Lee 1993), it is not clear whether the results would hold in a different cultural context. A replication study with a cross-cultural sample of respondents would definitely identify boundary conditions for the documented effect and increase the generalizability of this research.

\section{REFERENCES}

Aiken, L. S., \& West, S. G. (1991). Multiple Regression: Testing and interpreting interactions. Thousand Oaks, CA: Sage.

Alden, D. L., Hoyer, W. D., \& Lee, C. (1993). Identifying global and culture-specific dimensions of humor in advertising: A multinational analysis. Journal of Marketing, 57 (2), 64-75.

Apter, M. J. (1982). The experience of motivation: The theory of psychological reversals. New York, NY: Academic Press.

Beard, F.K. (2008). Humor in the advertising business: Theory, practice, and wit. Lanham, MD: Rowman \& Littlefield.

Cacioppo, J. T., \& Petty, R. E. (1982). The need for cognition. Journal of Personality and Social Psychology, 42 (January), 116-131.

Cacioppo, J. T., Petty, R. E., Feinstein, J. A., \& Jarvis, W. B. G. (1996). Dispositional differences in cognitive motivation: The life and times of individuals varying in need for cognition. Psychological Bulletin, 119 (March), 197-253.

Cacioppo, J. T., Petty, R. E., \& Kao, C. F. (1984). The efficient assessment of need for cognition. Journal of Personality Assessment, 48 (June), 306-307.

Chattopadhyay, A., \& Basu, K. (1990). Humor in advertising: The moderating role of prior brand evaluation. Journal of Marketing Research, 27 (November), 466-476.

Cline, T. W., Altsech, M. B., \& Kellaris, J. J. (2003). When does humor enhance or inhibit ad responses? Journal of Advertising, 32 (3), 31-45.

Cline, T. W., \& Kellaris, J. J. (1999). The joint impact of humor and argument strength in a print advertising context: A case for weaker arguments. Psychology \& Marketing, 16 (January), 69-86.

Dickhäuser, O., \& Reinhard, M.-A. (2006). Factors underlying expectancies of success and 
achievement: The influential roles of need for cognition and general or specific self-concepts. Journal of Personality and Social Psychology, 90 (March), 490-500.

Fletcher, G. J. O., Danilovics, P., Fernandez, G., Peterson, D., \& Reeder, G. (1986). Attributional complexity: An individual differences measure. Journal of Personality and Social Psychology, 51 (October), 875-884.

Geuens, M., \& De Pelsmacker, P. (2002). The role of humor in the persuasion of individuals varying in need for cognition. Advances in Consumer Research, 29 (1), 50-56.

Gruner, C. R. (1996). Wit and humour in mass communication. In A. J. Chapman \& H. C. Foot (Eds.), Humor and laughter: Theory, research, and applications (pp. 287-312). New Brunswick, N.J.: Transaction Publishers.

Hayes, A. F. (2013). Introduction to mediation, moderation, and conditional process analysis. New York, NY: Guilford.

Kellaris, J. J., \& Cline, T. W. (2007). Humor and ad memorability: On the contributions of humor expectancy, relevancy, and need for humor. Psychology \& Marketing, 24 (6), 497-509.

Koestler, A. (1964). The Act of Creation. Oxford, UK: Macmillan.

Martin, R. A. (1998). Approaches to the sense of humor: A historical review. In W. Ruch (Ed.), The sense of humor: Explorations of a personality characteristic (pp. 15-60). Berlin, Germany: De Gruyer.

Martin, R. A. (2007). The psychology of humor: An integrative approach. Burlington, MA: Elsevier.

Petty, R. E., \& Cacioppo, J. T. (1981). Attitudes and persuasion: Classic and contemporary approaches. Dubuque, IA: William C. Brown.

Petty, R. E., Schumann, D. W., Richman, S. A., \& Strathman, A. J. (1993). Positive mood and persuasion: Different roles for affect under high- and low-elaboration conditions. Journal of Personality and Social Psychology, 64 (January), 5-20.

Raskin, V. (1985). Semantic mechanisms of humor. Dordrecht, Holland: D. Reidel Publishing.

Ruch, W., \& Hehl, F.-J. (1998). A two-mode model of humor appreciation: Its relation to aesthetic appreciation and simplicity-complexity of personality. In W. Ruch (Ed.), The sense of humor: Explorations of a personality characteristic (pp. 109-142). Berlin, Germany: DeGruyer.

Ruch, W. (1988). Sensation seeking and the enjoyment of structure and content of humour: Stability of findings across four samples. Personality \& Individual Differences, 9 (5), 861-871.

Simpson, P. (2003). On the discourse of satire: Towards a stylistic model of satirical humour. Amsterdam: John Benjamins. 
Speck, P. S., (1991). The humorous message taxonomy: A framework for the study of humorous ads. Current Issues \& Research in Advertising, 13 (1), 1-44.

Weinberger, M. G. \& Gulas, C. S. (1992). The impact of humor in advertising: A review. Journal of Advertising, 21 (4), 35-59.

Zhang, Y. (1996a). Responses to humorous advertising: The moderating effect of need for cognition. Journal of Advertising, 25 (1), 15-32.

Zhang, Y. (1996b). The effect of humor in advertising: An individual difference perspective. Psychology \& Marketing, 13 (6), 531-545. 